\title{
Ida y vuelta de Octavio Paz a José Luis Martínez: notas sobre una amistad manifiesta en un epistolario
}

\section{Adolfo Castañón}

\section{Nota aclaratoria}

En el año 2014 se celebraron en Hispanoamérica los centenarios del nacimiento de tres grandes escritores: Julio Cortázar, Adolfo Bioy Casares y Octavio Paz. Numerosas fueron las evocaciones, los coloquios, los ensayos, los testimonios y, sobre todo, la gratitud comprensiva hacia obras literarias que durante el siglo XX configuraron, con rasgos indelebles, el imaginario latinoamericano. En México el homenaje a Octavio Paz, que recibió el premio Nobel de literatura en 1990, fue una cuestión de Estado y se extendió durante todo el 2014. El Secretario de Educación Pública del gobierno de entonces, Lic. Emilio Chuaytfett Chemor, y el Presidente de CONACULTA, Lic. Rafael Tovar y de Teresa, entre otras autoridades del ámbito de la cultura mexicana, dieron a conocer el vasto programa de la Celebración del Centenario del Natalicio de Octavio Paz, en el tradicional y majestuoso Palacio de Bellas Artes. Incluía ediciones de libros, actos diversos, debates, exposiciones de arte, una Cantata, un retrato hablado del poeta a cargo de 21 amigos en el escenario del Palacio de las Artes, la visita de homenaje de otros premios Nobel de literatura (Le Clézio, Wole Soyinka y Derek Walcott), un recital de poesía internacional, etcétera.

Entre tantos actos que poblaron la escena sociocultural del país, El Colegio de México convocó, ideado por el crítico e investigador y uno de los grandes especialistas en Paz, Anthony Stanton (integrante del Centro de Estudios Lingüísticos y Literarios de esa institución) al Coloquio Internacional "Octavio Paz: el poeta y el ensayista en su centenario". Entre los estudiosos invitados, el escritor Adolfo Castañón participó con una conferencia el día 12 de septiembre de 2014. Su texto versaba sobre la correspondencia mantenida entre Octavio Paz y José Luis Martínez. Al profundo y delicado análisis de aquel epistolario, realizado con su habitual agudeza por Castañón, se agregó una particularidad retórica que la audiencia de aquella mañana celebró: el ensayo tenía la forma misma de una carta dirigida a Anthony Michael Stanton, allí presente. Aquel ensayo, de extraordinario valor crítico y documental, circuló algún tiempo por la red pero, hasta el momento, no había sido formalmente editado y publicado. El propio Adolfo Castañón lo ha cedido ahora, muy generosamente, para reproducirlo en este número 11 de nuestra revista, que ahora lo presenta a todos sus lectores. Por tratarse de un texto especial, mantenemos las notas al pie tal como las dispuso el autor. 
1. Texto leído en el Coloquio Internacional "Octavio Paz: el poeta y el ensayista en su centenario" en El Colegio de México el día viernes 12 de septiembre de 2014 en la Mesa 4: "Corresponsal, prologuista, crítico de arte a las 10:0o horas". El autor agradece a Rodrigo Martínez Baracs, Malva Flores y Guillermo Sheridan sus observaciones y contribuciones.

2. Octavio Paz y José Luis Martínez. Al calor de la Amistad. Correspondencia 1950-1984, edición de Rodrigo Martínez Baracs, Colección Tezontle, Fondo de Cultura Económica, México, 2014, 219 pp.

\section{Ida y vuelta de Octavio Paz a José Luis Martínez: notas sobre una amistad manifiesta en un epistolario ${ }^{1}$}

\author{
México, D. F., 12 de septiembre de 2014 \\ Dr. Anthony Michael Stanton \\ Centro de Estudios Lingüísticos y Literarios de El Colegio de México.
}

\section{Querido Anthony:}

Gracias por haberme invitado al Coloquio Internacional dedicado a Octavio Paz en el marco de su centenario por el Centro de Estudios Lingüísticos y Literarios de El Colegio de México. Te pido que por favor les des las gracias también a la doctora Luz Elena Gutiérrez de Velasco, directora del Centro, y al doctor Javier Garciadiego. También aprovecho para felicitarte por la organización misma del coloquio y por la elección de los invitados y temas propuestos que cubren tramos y esferas emblemáticas y significativas de la galaxia poética y cultural llamada Octavio Paz. Transmite también mi agradecimiento a nuestro querido amigo y poeta Eduardo Lizalde por sus palabras en la conferencia inaugural.

Gracias también, querido Anthony, por haber aceptado sin vacilación que me ocupara de un tema y de un libro relativamente menor pero, a mis ojos, muy significativo y comprehensivo: el de la correspondencia 1950-1984 titulada Al calor de la amistad, ${ }^{2}$ en edición de Rodrigo Martínez Baracs, hijo de don José Luis Martínez, historiador y amigo nuestro.

\section{I}

El tema de los epistolarios, como tú bien sabes pues tuviste la fortuna de preparar la correspondencia cruzada entre Alfonso Reyes y Paz publicada en 1998 bajo la mirada y supervisión del propio Octavio, no es en modo alguno un tema menor, si bien la teoría literaria actual sitúa al género autobiográfico, a los géneros autobiográficos, en una clave secundaria en relación con la "obra" propiamente dicha. Es cierto también, y tú lo sabes, que hay quienes discrepan de esta posición y confieren a la carta, en particular, un estatuto hermenéutico superior en la medida en que en una carta no hay, no puede haber, lugar a la ficción, en la medida en que la exigencia de veracidad y de reciprocidad sitúan a la carta en un estatuto ético que resulta superior, pues en una carta está invariablemente puesto, expuesto y apostado el otro, los otros. Cartas fueron algunos de los Evangelios, como cartas fueron también algunos de los textos centrales del Renacimiento, para no hablar de esos monumentos iconográficos y gráficos que son las cartas de los artistas, como por ejemplo Vincent van Gogh. No te voy a asestar en este pliego una teoría de la carta aunque sepas cuánto aprecio y pondero el género, casi tanto, guardando todas las proporciones, como Alfonso Reyes, Octavio Paz y José Luis Martínez mismo...

$\mathrm{Al}$ asunto general de los epistolarios de Octavio Paz todavía le hace falta mucho trabajo y maduración editorial y crítica. Cierto: Paz no fue ajeno en modo alguno al género y se tienen ya algunos ejemplos de la forma en que el juego de verdad del epistolario era practicado por él, desde las cartas a su primera esposa, Elena Garro, hasta las cartas literarias, poéticas, políticas y aun editoriales. Un caso notable en este sentido es el de las Cartas cruzadas con Arnaldo Orfila entre 1965 y 1970 donde se despliegan los estira y afloja en torno a la antología colectiva titulada Poesía en movimiento, al cuidado del propio Paz, Alí Chumacero, José Emilio Pacheco y Homero Aridjis, amén y a más del propio Orfila, tanto como se documenta el proceso editorial del gran pequeño libro Posdata. Por cierto, querido y estimado Anthony, ¿te has dado cuenta 
de que existe una tentación hacia la creación colectiva tanto en el poema eslabonado en cuatro lenguas titulado Renga (1969) y este corpus polifónico también cocinado a cuatro voces que son las analectas de Poesía en movimiento (1966)? Concederás, querido Anthony, que en esta materia de la identidad plural en Octavio Paz hay no poca tela de dónde cortar. Vuelvo a mis timbres: otros casos de correspondencia son, como se sabe, los de las cartas de Octavio Paz a Tomás Segovia, Pere Gimferrer, Jean-Clarence Lambert, entre los más visibles. Lastima a la sensibilidad del historiador que quiere tener a la vista las diversas visiones de los hechos, que estos valiosos epistolarios resulten fragmentarios, pues en los casos de Tomás Segovia, Jean-Clarence Lambert y Pere Gimferrer, no se conocen las respuestas de estos a Paz, aunque en muchos casos se puedan adivinar entre líneas. Por lo demás, tenemos noticia y conciencia de que existen cartas, recados, notas dirigidos a un amplio abanico de autores, amigos y colaboradores, como: Julio Cortázar, José Gaos, Elena Garro, Alí Chumacero, María Zambrano, Waldo Frank, José Lezama Lima, José Bianco, Alejandro Rossi, Juan García Ponce, Carlos Fuentes, Jaime García Terrés, Ignacio Chávez, Charles Tomlinson, Juan Goytisolo, André Breton, Claude Gallimard, Bona de Mandiargues, André Pierre, Ramón Xirau, Antonio Sánchez Barbudo, José Emilio Pacheco, Vicente Rojo, Fernando Benítez, Enrique Krauze, Rodolfo Usigli, Francisco Castillo Nájera, Hugo J. Verani, Enrico Mario Santí y, me imagino, querido Anthony, que debes de tener escondida por ahí alguna nota que Octavio Paz te hizo llegar.

\section{II}

Podría imaginarse que este libro, titulado acertadamente Al calor de la amistad, es como una urna votiva; se recogen aquí las cenizas y el sentido de dos amigos, es decir, de dos seres que se encontraron y eligieron perseverar en el encuentro. El volumen de 219 páginas consta de 76 cartas y 300 notas; 43 cartas de Octavio Paz a José Luis Martínez y 22 de este a aquel, a los que se suman algunos documentos. Las cartas de Paz suelen ser más extensas y elocuentes que las de su parco amigo. El epistolario cubre los 34 años que van de 1950 a 1984. Sin embargo la relación entre Paz y Martínez se remonta en el tiempo a años atrás, incluso antes de que Octavio Paz escribiera el poema "Delicia" dedicado a su amigo, incluido originalmente en A la orilla del mundo, poesía hispanoamericana, México, 1942 (pp. 148-149), y reproducido por Rodrigo Martínez Baracs en este epistolario en las páginas 135-136. El poema fue reescrito por Paz en 1960 en Libertad bajo palabra (pp. 59-60) y retomado más tarde en Obra poética I (pp. 42-43). Como tú bien sabes, querido Anthony, estas Primeras voces del poeta Octavio Paz, para frasear un título tuyo sobre la producción en el periodo de aprendizaje en el joven Octavio de Luna silvestre (1933), de Raíz del hombre (1937) y de A la orilla del mundo (1942), se da en esos poemas un contrapunto entre el asombro, el deporte y el dominio de las formas, como, por lo demás, también lo supo ver Hugo J. Verani al reseñar tu libro sobre este tema, ${ }^{3}$ ¿verdad? Me voy a dar el lujo de transmitir ese poema del joven Octavio Paz para darle la palabra a aquél joven "enamorado de la realidad sensible de este mundo". Nos obligaré a releerlo con los oídos.

\section{DELICIA}

Como en el mar desierto surge, de entre las olas, una que se sostiene, estatua repentina, sobre las verdes, líquidas espaldas de las otras, las sobrepasa, vértigo solitario, y a sí misma, a su caída y a su espuma, se sobrevive, esbelta, y hace quietud su movimiento,
3. Hugo J. Verani, reseña de "Las primeras voces del poeta Octavio Paz (1931-1938)", de Anthony Stanton, Nueva Revista de Filología Hispánica, El Colegio de México, Centro de Estudios Lingüísticos y Literarios, tomo LII, núm. 1, 2004, pp. 227-228. 
reposo su oleaje,

tú, delicia, imprevista criatura,

brotas entre los ávidos minutos,

alta quietud erguida, suspensa eternidad.

Entre conversaciones o silencios,

lenguas de trapo y de ceniza,

entre las reverencias, dilaciones,

las infinitas jerarquías

los escaños del tedio, los bancos del tormento,

naces, poesía, delicia,

y danzas, invisible, frente al hombre.

El presidio del tiempo se deshace.

¿Cómo tocarte, impalpable escultura?

¿Cómo, si solo movimiento,

quedas así, tensa y estable, inmóvil?

Si música, no suenas; si tiempo, no transcurres;

¿qué te sostiene, líquida?

¿de qué alma brotaste, venganza del hastío,

flor del horror, del tedio, de la nada?

Por ti, delicia, poesía,

breve como el relámpago,

el mundo sale de sí mismo

y se contempla, puro, desasido del tiempo.

Pueblas la soledad del solitario

y en el arrobo aíslas al hombre encadenado.

Y los sentidos palpan

la rumorosa forma presentida

$\mathrm{y}$ ven los ojos lo invisible

y en círculos concéntricos el sonido se ahonda

hasta clavarse en el silencio,

flecha que retrocede hacia su origen...

El tiempo muestra sus entrañas huecas:

de su insomne vacío

surges, perdido paraíso,

sepultado secreto de este mundo.

No necesito decirte, querido Anthony, que es inútil que busques esta versión de 1942 en las obras completas. Tampoco me permitiré señalar los ecos y afinidades de aquel poema con la poesía de Rafael Alberti, Gerardo Diego, Lope de Vega y Garcilaso, ni la forma en que el joven Octavio Paz les tiende la mano tanto a los vivos como a los difuntos...

El poema "Delicia" fue dedicado por Octavio Paz a José Luis Martínez "al preparar la edición que ha hecho Seix Barral" (1976). Paz le envía a Martínez una carta fechada el 26 de junio de 1979 (carta número 68, p. 115). Al final de la carta dice Paz:

Escribí este poema en una oficina -las infinitas jerarquías, los troncos del tormento, etcétera- probablemente en la Comisión Nacional Bancaria. Tema para un futuro historiador de nuestra literatura: Burocracia y Poesía...

La respuesta de José Luis Martínez no se hace esperar:

En México, 16 de julio de 1979

Querido Octavio: me has hecho un regalo que me emociona al dedicarme, en tu carta 
del 6 de junio, tu poema "Delicia". Me gustaba, hace ya tantos años, y me sigue gustando por su gracia luminosa de la transfiguración que expresa. Creo que es uno de tus poemas de juventud que elegiría para representar una de las primeras estaciones de tu poesía, que luego se ha enriquecido con tantas otras.

He repasado el proceso de concentración y desnudamiento de "Delicia" en sus tres versiones: La primera de A la orilla del mundo (1942), la que aparece en la segunda Libertad bajo palabra (1960), y ahora esta de 1979. Los primeros retoques de 1960 convencen de su necesidad — una vez vistos - y dejan más terso el poema que aún sigue siendo el mismo inicial, de íntimo y elocuente lirismo. En cambio, los recientes son ya algo más que correcciones: son una reelaboración, cuya maestría admiro. Con pulso firma sacrificas versos preciosos y de hecho las dos últimas estrofas, que rescribes luego en tres versos finales. Por supuesto, el mismo poema, considerando el vuelo de las dos estrofas iniciales, se cierra con más concentrada intensidad. Pero lo que aún tengo de sentimental me hace echar de menos la antigua cuarta estrofa, ahora tachada, en que describías el arrobo, la transfiguración:

Por ti, delicia, poesía

breve como el relámpago,

el mundo sale de sí mismo

y se contempla, puro, desasido del tiempo.

Pueblas la soledad del solitario

y en el arrobo aíslas al hombre encadenado.

Y los sentidos palpan

la forma presentida

$\mathrm{y}$ ven los ojos lo que inventan

y en círculos concéntricos el sonido se ahonda

Hasta clavarse en el silencio.

Así pues, creo que pueden ser válidas las dos versiones de "Delicia", la de 1942-1960 y esta de 1979, como creaciones de dos etapas de una evolución poética.

Lydia y yo los saludamos con cariño, y con mi reconocimiento va mi antigua amistad.

José Luis. ${ }^{4}$

A José Luis Martínez siempre le había gustado este poema. Fue escrito después de 1938, luego de su regreso de España, fecha en la que Octavio Paz empezó a trabajar en la Comisión Nacional Bancaria, quemando billetes gastados y viejos. En la voz de Octavio Paz, recreada por Julio Hubard, aquel episodio se lee así:

Nos pagaban por contar billetes inservibles que, ya contados, se guardaban en sacos" - dice la voz de Octavio Paz recreada por el poeta y traductor Julio Hubard-; "cada mes se encendía un gran horno que estaba en la azotea del Banco de México y se consumían millones de billetes. Algo infernal. El dinero es una abstracción, un símbolo, pero aquel símbolo se convertía en un papel sucio que había que quemar:

Madura en el subsuelo

la vegetación de los desastres

y a la altura de los desastres

queman millones y millones de billetes viejos en el Banco de México.

Para no contraer enfermedades, usábamos unos guantes rojos de hule. Yo no podía contar bien, siempre me sobraban o faltaban billetes. Al principio, aquello me angustiaba, pero después decidí que el mundo no se empobrecía o enriquecía más si faltaban cinco o seis billetes. Por último decidí no contar y me pasaba las horas componiendo poemas mentalmente. ${ }^{5}$
4. Al calor de la amistad, pp. 115-118.

5. Julio Hubard, También soy escritura. Octavio Paz cuenta de sí, pp. 61-62. 
Al parecer Octavio Paz no solo componía poemas en la mente; también empezó a contar sílabas y estrofas con mayor exactitud que los montones de inservible papel moneda; a esa época se remonta la fundación de la revista Taller y la escritura de este poema "Delicia" que podría haber sido escrito por un poeta de la generación española de 1927.

Gracias a la nota del editor se puede precisar la fecha en que Paz y Martínez se conocieron: fue en 1939. El poema "Delicia" fue publicado el 15 de enero de 1942. Probablemente Martínez "quedó fascinado por el poema 'Delicia”" (p. 197). Al escribir "Delicia", en 1942 Octavio Paz tenía 28 años, mientras que su joven amigo llegado poco antes de Jalisco a la ciudad de México, estudiante de medicina, José Luis Martínez, tendría alrededor de 24. No me atrevo a decirlo, querido Anthony, pero conociendo a don José Luis Martínez, es probable que se supiera de memoria algunos versos de este poema si no todo. Era la época de las revistas Letras de México, Taller, El hijo pródigo, Romance; pero Paz acababa de regresar de su viaje a la España tenebrosa e incendiada de 1938; se había casado con Elena Garro Navarro en 1937 y en 1939 había visto nacer, un 20 de noviembre, a su hija Laura Elena Paz Garro, como oportunamente informa Rodrigo Martínez (p. 156 n. 12 a la carta No. 3 del 22 de enero de 1957). Curiosamente, Octavio y Elena se casaron en la casa de Amalia Navarro y Lamberto Hernández, los padres de la coreógrafa Amalia Hernández Navarro (1917-2000), quien sería la primera esposa de José Luis Martínez entre 1944 y 1950. Estas coincidencias no tendrían mayor valor si no se hubiese dado un trasfondo más profundo.

\section{III}

Octavio Paz Lozano (1914-1988) y José Luis Martínez Rodríguez (1918-2007) fueron amigos y tuvieron amigos, paisajes y afinidades en común: buscaron comprehenderse a lo largo del tiempo, compartían una curiosidad pluriversal, cada uno a su manera era versátil y estaba marcado por una voraz vocación artística y filosófica. Cabría cotejar, por ejemplo, la lista de los autores preferidos por ambos en aquellas épocas y recogidos en lo que hace a Paz en Miscelánea I y en lo que hace a Martínez en Primicias (2008): Montaigne y los moralistas franceses, Rilke, Gide, Reyes, D. H. Lawrence, etcétera. Compartieron, además, la amistad de algunos autores mayores de edad que ellos, como Alfonso Reyes y Xavier Villaurrutia, la de algunos contemporáneos como Alí Chumacero y Jorge González Durán, con los cuales por cierto, Octavio Paz también sostuvo correspondencia.

\section{IV}

Querido Anthony, convendrás en que la amistad, esa categoría afectiva que en la antigüedad clásica se ponía por encima no solo del amor, sino incluso de la lealtad a la ciudad o a la tribu, no es nunca fortuita ni accidental. Menos lo fue en este caso: se tradujo en una profunda confianza, una familiaridad y trato cuidadoso y práctico que hizo de ellos a la larga como el núcleo de una pequeña familia. Esto lo sabe ver muy bien Rodrigo Martínez cuando, en la nota 11 (p. 156), evoca las reuniones del grupo de amigos ("Los Divinos") que se reunían primero en el "Bar Alfonso, en el Centro en la calle de Motolinía 18, esquina con 5 de Mayo" y más tarde en el restaurante Bellinghausen. Esta confianza resulta palpable en el presente intercambio. Aparecen muchas veces asuntos prácticos que tienen que ver con las finanzas o encargos delicados, que van desde la recomendación de una persona particular (por ejemplo Perla Pourcell, véase el anexo sobre el tema más adelante) hasta la solicitud de reservación confidencial de un hotel en París, cuando Octavio Paz viaja, en 1964, desde la India a encontrarse, sin saberlo, dos veces con su destino: con el Premio Internacional de 
Poesía otorgado por la Bienal de Knokke-le-Zoute, en Bélgica, por El arco y la lira (al que fue propuesto por José Luis Martínez: "Propuse a Octavio y lo ganó", nota 49, p. 164) y con Marie José Paz, con la que se encuentra por azar en París a fines de junio de 1964, es decir, hace cincuenta años, según lo recordará Octavio Paz en Viento entero:

El presente es perpetuo

Se abren las compuertas del año

el día salta ágata

El pájaro caído

entre la calle de Montalambert y la de Bac

es una muchacha

detenida

sobre un precipicio de miradas. ${ }^{6}$

Paz se encontraba en la fuerza de su edad. En otra carta de Martínez al poeta Jorge Hernández Campos, que me ha sido facilitada por Rodrigo, se retrata así a esta excepcional fuerza de la naturaleza.

“[París] 9 de julio de 1964

$[\ldots]$

En París nos esperaba nuestro poeta, Octavio Paz, lleno de imágenes de la India, de cordialidad y de proyectos. O el yoga o el curry o la vieja sabiduría erótica han conspirado para mantenerlo tan joven de cuerpo como de alma. Anda ya sobre sus cincuenta pero se diría que ha vuelto a sus treintas y, consiguientemente, a pensar y a querer con el entusiasmo de aquella edad. Lo hemos visto mucho, algo hemos conversado y más lo hemos escuchado, porque vale la pena hacerlo. Lo acompañamos a Bruselas, para recibir su Premio Internacional de Literatura y, una vez pasadas las glorias belgas y comido obsenamente [sic.], nos fuimos a Brujas para ver otra vez Los Memlings del Hospital San Juan y los demás flamencos del Museo Comunal y comprobar que, en el estilo nórdico, Brujas es acaso la ciudad más hermosa, más enfermiza y obsesionante. [...]. ${ }^{7}$

7. Carta inédita comunicada por Rodrigo Martínez a A.C.

\section{V}

No me resulta fácil, querido Anthony, leer este epistolario. Al igual que tú, tuve la fortuna de conocer y tratar, tanto a Octavio Paz como a José Luis Martínez. No es sencillo hablar de los amigos y maestros muertos. Lo decía de otro modo Alejo Carpentier: en América tenemos la fortuna de ser contemporáneos de nuestros clásicos, y nosotros, querido Anthony, contemporáneos de nuestros maestros que se han ido. Quizá no fuera necesario el conocimiento de estas cartas, en última instancia privadas, para saber que Octavio Paz y José Luis Martínez compartieron preferencias y afinidades: ambos fueron hombres orquesta, intelectualmente ubicuos y, además, apasionados y devotos de la historia y de la cultura de México, como resulta ostensible a lo largo de este epistolario pero en particular de las cartas finales desde 24 de noviembre de 1982 en adelante. No en balde Octavio Paz consagró a Sor Juana Inés de la Cruz una obra que es un parteaguas en el conocimiento no solo de la vida de la monja y poeta y del saber acerca de la cultura virreinal, sino una de las grandes construcciones de la crítica literaria escrita en español y en otros idiomas. Por su parte, José Luis Martínez le dedicó a la azarosa vida de Hernán Cortés el gran libro decisivo que conocemos. Llama la atención un hecho: tanto Sor Juana como Hernán Cortés son figuras a la vez esenciales y difíciles de ajustar en la perspectiva didáctica convencional, su 
8. Al calor de la amistad, carta de José Luis Martínez a Octavio Paz del 24 de junio de 1981, p. 120.

9. Al calor de la amistad, p. 199.

10. Al calor de la amistad, p. 128. conocimiento compromete y supone una poda de la historiografía previa acumulada, una purga de los lucrativos lugares comunes. Esa poda, esa arte cisoria y crítica es una de las afinidades que unieron a Octavio Paz y José Luis Martínez en su pasión por la exactitud y en su práctica de la amistad. Ambas obras presuponen años de trabajo, de pasión callada y laboriosa, de paciente inclinación para recrear y restituir mundos en apariencia desaparecidos, pero cuya energía sigue latiendo bajo la superficie.

En este epistolario afloran al final ciertos detalles poco conocidos en relación con la escritura del libro de Sor Juana Inés de la Cruz por Octavio Paz. Por ejemplo, el hecho de que el poeta terminó su redacción sobreponiéndose a un agobiante malestar, quizá herpes: "Espero que esa dolencia atroz que te agobiaba sea ya solo un mal recuerdo, que pronto olvides. Y te distraigo con algunos envíos y noticias. Va una copia del folleto del homenaje de La Academia Española a Sor Juana que me pediste". ${ }^{8}$

Oportunamente el editor de esta correspondencia, Rodrigo Martínez Baracs, hace saber que probablemente se trataba de "el folleto del homenaje de la Academia Española a Sor Juana [... 'Homenaje a Sor Juana Inés de la Cruz', Boletín de la Real Academia Española XXXII (1952)".9 También queda claro que Martínez era capaz de hacer precisiones y puntualizaciones al gran poeta mexicano en puntos específicos de la edición de su libro sobre Sor Juana: "Me conmueve de veras la atención con que has leído mi ensayo acerca del arte mexicano y mi libro sobre Sor Juana Inés de la Cruz. Ante tus amonestaciones, benévolas pero justas, siento que me brotan invisibles orejas de burro. Resabios infantiles". ${ }^{10}$

La amistad podría leerse así como un puente que nos tiende el otro hacia nuestra propia infancia cuando nos señala con exactitud alguna falla. Paz sabía que podía contar con la amistad y admiración de José Luis Martínez desde el momento en que el jalisciense polemizó con decisión y firmeza contra Manuel González Ramírez desde la revista Voz, número 44, 19 de octubre de 1950, acerca de quién era el mejor poeta de México. Martínez fue, como recuerda Rodrigo, uno de los tres "primeros en reconocer el porvenir como gran poeta de Octavio Paz"; los otros dos habían sido Bernardo Ortiz de Montellano, en Contemporáneos en 1931 y Jorge Cuesta en 1937 en Letras de México, al reseñar "Raíz del hombre". Esta trama va aflorando tanto en las cartas como en las notas que lasacompaña.

Era natural y casi necesario que Octavio Paz y José Luis Martínez fueran amigos. Amigos pero no, al menos superficialmente, semejantes. Por distintas puertas de entrada los unía la fatal relación entre burocracia y poesía. Esto no impidió, desde luego, que desde una fecha muy temprana en "La vida literaria" la columna de José Luis Martínez en la revista Voz, número 44 del 19 de octubre de 1950, un intrépido Martínez de 38 años se encarara con Manuel González Ramírez para recalcar el parecer de que "Octavio Paz es el mejor poeta de México". Tenían en común, como se ha dicho, una admiración: la de Alfonso Reyes. Paz admiraba y quería al autor de Visión de Anáhuac, aunque a nadie se le hubiera ocurrido decir que "estudiaba para Alfonso Reyes", cosa que sí llegaron a decir, las malas lenguas, de José Luis. Alfonso Reyes, como es sabido, adoptó literariamente a Martínez y lo invitó a colaborar en el proyecto de una historia de la literatura mexicana que le había encargado Jaime Torres Bodet y que se publicaría con el título de México y la cultura (el ensayo se recogería más tarde en Letras de Nueva España, XII, Obras completas) mientras que a Martínez le tocaría hacer la parte correspondiente a la literatura mexicana del siglo XIX. En 1955, como bien recordarás, estimado Anthony Stanton, Martínez publicaría su libro Problemas literarios en la "Colección Literaria Obregón" dirigida por Octavio Paz y Carlos Fuentes. Pero Alfonso Reyes, le había escrito a Martínez ya desde el 25 de marzo de 1946 una carta saludando, en la revista El hijo pródigo, la aparición de uno de los ensayos incluidos en ese libro auspiciado por Paz y Fuentes: "Algunos 
problemas de la historia literaria". ${ }^{11}$ Como sabe cualquier alumno tuyo, querido Anthony, uno de los redactores de la revista era precisamente Octavio Paz, y no debe haber pasado por alto ese saludo emitido por el maestro autor de El deslinde, saludo que, convendrás tú, en cierto modo encuadra parte de la problemática crítica propuesta más tarde por El arco y la lira. Si entre Alfonso Reyes, Paz y Martínez se dibuja un triángulo crítico, la figura de Xavier Villaurrutia perfilará mejor el cuadro de estos paralelos y simetrías. En su libro Xavier Villaurrutia en persona y en obra, Octavio Paz hace ver hasta qué punto el autor de los Nocturnos se presentó ante sus ojos juveniles como un guía y un maestro iniciador. Por su parte, uno de los primeros textos de José Luis Martínez, sería una entrevista a Xavier Villaurrutia, quien, como poeta, no solo sería un modelo para Octavio Paz, sino también, y sobre todo, como poeta, prosista y crítico, para José Luis Martínez y su amigo Alí Chumacero, esa eminencia gris de la poesía mexicana en la cual juegan subterráneamente el decoro y la experimentación.

El breve pero muy jugoso epistolario intercambiado por José Luis Martínez y Octavio Paz está erizado de noticias y alusiones que ponen sobre la mesa la vida de dos amigos ejemplares a quienes no supieron separar episodios tan decisivos como el de 1968 en México y en el mundo. Martínez publicaría en la Revista de la Universidad de México octubre de 1967 a febrero de 1968 un artículo titulado "Nueva novela y nueva sensibilidad" en el que aludía a Octavio Paz según le escribe en la carta número 60 del 18 de mayo de 1968. A esta misiva responde Octavio Paz desde Kasauli en los Himalayas la carta 61 del 6 de junio de 1968 donde Paz se refiere con amplitud al tema del "cambio" y las visiones generacionales de poetas y prosistas, temas que acababa de tocar hacía unos meses al redactar el prólogo a Poesía en movimiento.

Octavio Paz a José Luis Martínez, Kasauli,

6 de junio de 1968 (manuscrito)

EMBAJADA DE MÉXICO [Impreso]

Kasauli, a 6 de junio de 1968

Querido José Luis:

Tu carta nos alcanza en estas soledades de los Himalayas, no menos hermosas que las de Góngora y más transparentes, más altas.

Gracias por haber acogido a Duvignaud. Gracias también por los dos ejemplares del álbum de Tamayo: tienes razón, lo mejor será que los guardes hasta nuestro regreso. (Por cierto: mi texto no es un ensayo sino un poema.)

No reviso aún el número de la Revista de la Universidad en que aparece tu ensayo sobre la literatura joven. Un tema difícil: el criterio meramente biológico de juventud no es aplicable a la literatura -lo que cuenta es el cambio, independientemente de la edad: el viejo Whitman tanto como el adolescente Rimbaud, el Mallarmé de Un coup de dés o el joven Apollinaire. La literatura es joven cuando los autores, sean jóvenes o viejos, cambian el lenguaje de una época -en el sentido más amplio y radical de la palabra lenguaje: la visión del mundo y de las cosas. Si se piensa en Carlos Fuentes, Jaime Sabines, Tomás Segovia, Salvador Elizondo, Zaid, Montes de Oca y otros pocos más (novelistas y poetas) sí puede decirse que en México existe una nueva (joven) literatura. Otro problema (o mejor dicho: uno de los rasgos que hacen nueva a nuestra literatura): la interdependencia de los géneros. ${ }^{12}$ Por ejemplo: los novelistas, por primera vez en nuestro país, aprovechan la lección de la poesía -se dan cuenta de que la novela es un género poético. En este sentido Fuentes (y antes Rulfo), representan un cambio radical: son los primeros que conciben a la novela como un organismo verbal regido por leyes propias (aunque análogas a los del poema lírico). La novela no renuncia al realismo: es un mundo. Por su parte, los poetas jóvenes no
11. "A José Luis Martínez", Obras completas, tomo VIII, De viva voz, p. 81 .
12. Mejor dicho: su disolución, su fusión... (a la vuelta). [Nota de Octavio Paz] 
han sido insensibles a las conquistas de la novela: la poesía cuenta, relata -más exactamente: presenta- en una forma que no es esencialmente distinta a la de la novela. Fusión de géneros. De ahí que todo examen de la situación actual tenga que ser de carácter global: no la antigua crítica académica de géneros sino las relaciones (oposiciones y afinidades) entre las obras importantes, cualquiera que sea su género. Una época es un lenguaje y ese lenguaje se manifiesta por igual en el teatro y en la pintura, en la ficción y la poesía. Otro tema (otro rasgo distintivo) de la nueva literatura: su carácter crítico. Crítica de la sociedad y crítica del lenguaje: poesía crítica. A la inversa de lo que ocurrió con la literatura "revolucionaria" del pasado inmediato, la nueva literatura, por ser crítica, es realmente rebelde y profundamente revolucionaria — no critica abusos y desviaciones como Martín Luis Guzmán o Azuela sino que muestra las estructuras profundas de la mentira que nos ahoga y profana los valores. Esta crítica profanadora también opera en un sentido distinto a la de Contemporáneos: no es en rigor destinada a preservar el lenguaje sino a violarlo. Profanación y violación son, no obstante, maneras negativas de describir a la nueva literatura mexicana: la violación es un rito y la profanación una suerte de consagración. De ahí la importancia de la forma tanto en los novelistas como en los poetas, su preocupación por el lenguaje, su amor por la experimentación y su rebeldía moral. Pero no sé por qué hablo de todo esto: tú sabes mejor que yo cuál es el estado de nuestras letras. Por supuesto, mi visión es parcial: soy parte del movimiento Mientras escribo estas líneas, la B. B. C. de Londres nos confirma la muerte de Robert Kennedy. Los pistoleros como factores decisivos en la política mundial... Y la admirable actitud de los estudiantes en Francia, Yugoslavia y otras partes: ocurra lo que ocurra, avanza la profanación consagradora. La revuelta juvenil es uno de los signos más seguros de la mutación de nuestra sociedad - a veces me parece que regreso a los años 30 .

Saludos de los dos a los dos, con un doble abrazo

Octavio

P.S. Ayer me comunicó mi abogado que, como yo preveía, gané el juicio. Nos veremos en noviembre y ya hablaremos. ¿Todavía existe tu Revista de Bellas Artes? Ejemplos, en la poesía: el último poema de Segovia, los libros de Aridjis, Piedra de Sol, Viento entero, el prosaísmo de Salinas; en la prosa: Zona Sagrada, Cambio de piel, la novela de Elizondo, [las experiencias verbales y de escritura de Sainz], el último libro de Pacheco (excelente) y esa novela de Echeverría (Último sol) en la que el lenguaje se vuelve sobre sí mismo, como en algunos poemas recientes que prefiero no citar. También hay que citar otra característica: la crítica, social en Monsiváis, estética en García Ponce (es un crítico mejor que Villaurrutia - además de ser un excelente cuentista), literaria y moral en Zaid. Por último, algunos de los nuevos poetas (Mondragón, Montes de Oca, etc.) se sienten artífices: para ellos el arte es inseparable de la tarea de cambiar al mundo... El común denominador de todo esto, me decía Carlos Fuentes en carta reciente, es la poesía. ${ }^{13}$

La siguiente carta, número 62, enero de 1969, es un mensaje de un empleado de la Secretaría de Hacienda y Crédito Público fechado en enero de 1969 donde se da cuenta a la Aduana de la siguiente solicitud:

ADUANA VERACRUZ, VER.

301-I-4313.-Solicitud Secretaría Relaciones Exteriores y fundamento decreto siete enero 1936, autorízase franquicia importación un Lift Van conteniendo menaje casa y efectos personales del señor Octavio Paz, Embajador de México en la India. P.O. Director 
El Jefe Depto. Procedimientos

José Medina Bernal

La redacción de este despacho no puede ser más burocrática, ni el hecho, estimado Anthony Stanton, más significativo: se está hablando ahí de que José Luis Martínez se ocupó del seguimiento de la mudanza que contenía todo el "menaje casa y efectos personales..." de Octavio Paz quien había renunciado a la India en octubre de 1968. La siguiente carta, la número 63 del 30 de abril de 1969 trae una carta poder de Josefina Lozano, viuda de Paz "A quien corresponda" para que se faculte a un encargado de ella, el señor Fernando Rosas Villa, para que se ocupe de dar seguimiento al envío citado antes y a dar cuenta del "estado de deterioro del envío citado". Como ves querido Anthony, la amistad puede llevar lejos. Después de la lectura de un epistolario como este, podría aconsejar, estimado Anthony, a quien se pusiese a hacer una biografía de Octavio Paz que leyera con lupa si no es que con microscopio, este admirable jardín cultivado por la amistad donde no solo se recogen las flores que nacen sino también, como diría la canción "Las hojas muertas".

\section{VI}

Si se concibe un epistolario como una casa, ese hogar se rige por las leyes de la hospitalidad, hospitalidad hacia el otro, hacia los amigos y amores del otro. Un epistolario refleja necesariamente el cambio y la mudanza. Aparece aquí el tema delicado del divorcio entre Octavio Paz y Elena Garro. En la carta del 7 de abril de 1965, dirigida por el poeta a su amigo, se hace mención explícita del tema del divorcio de Paz con Elena Garro:

He sabido (noticias indirectas pero que me merecen crédito) que quien tú sabes dice con frecuencia que nuestro divorcio no es "legal". Sé que a veces amenaza con intentar una acción judicial, destinada a anularlo. No creo que lo intente y sé que, si lo intentara, fracasaría: estoy seguro de la "legalidad" de mi divorcio - para no hablar de su legitimidad moral, sentimental y psicológica. De todos modos, deseo consultar el caso con un abogado. Como tú quizá sabes, la persona que se encargó de tramitar este asunto, mi amigo Raúl Vega, murió hace poco en un accidente. ¿Conoces a un abogado que sea de gran competencia, honradez y discreción? Sé que estás muy ocupado y de ahí que no te pida respuesta a mi carta: basta con que en una hoja de papel escribas el nombre del abogado y su dirección -y me la envíes a vuelta de correo. Gracias de antemano $[\ldots] .{ }^{14}$

La publicación de este epistolario dio lugar a que un notario mexicano diese a conocer la carta de condolencias que le escribió Octavio Paz a la viuda de su amigo Raúl Vega, muerto en marzo de 1964 en un accidente, compañero de los tiempos de Barandal, testigo en el matrimonio con Elena Garro en 1937 y autor del trámite del divorcio de su amigo en 1959, según da noticia Rodrigo Martínez en la nota a la carta arriba citada. Dice Octavio Paz a la viuda:

Delhi, a 27 de marzo de 1964

Señora Maria Luisa G., viuda de Vega

México, D.F.

Muy querida María Luisa:

Por carta de mi madre, recibida apenas hace dos días, me enteré de la muerte de Raúl. Me ha dolido muchísimo. Lo quise de verdad. Lo quisimos todos sus amigos. Para mí 
15. Carta tomada del artículo “El abogado de Octavio Paz" de Ángel Gilberto Adame López - Licenciado en Derecho por la UNAM y notario 233 del Distrito Federalpublicado en el periódico El mundo del abogado, 3 de agosto de 2014, sección "Reportaje”.
- y creo que para todos los que fuimos sus compañeros y lo tratamos de cerca- Raúl era sobre todo la amistad. Inteligente, sensible, irónico - esas cualidades, con ser muchas, pesaban menos que su generosidad y su corazón-. Con la ironía se defendía de la ternura - pero era sobre todo un hombre tierno-. Me imagino tu pena y la de tus hijos. Créeme que la de nosotros, sus amigos de toda la vida, también es muy profunda y sincera. Entre Raúl y yo jamás se interpuso una sombra. Siempre que acudía a él - en busca de consejo o de alegría - me abrió los brazos. Era tan generoso con su tiempo como con su inteligencia. Cuando regrese a México - yo, el solitario enorme, el alma en pena- lo echaré de menos. Raúl era el centro de muchos afectos y gracias a él nuestra adolescencia y juventud seguían vivas. No será fácil olvidarlo. Querida María Luisa: sepan Luz y tus hijos que yo permaneceré fiel a la memoria de Raúl y que la amistad que le tuve es también de ustedes.

Muy afectuosamente,

Octavio $\mathrm{Paz}^{15}$

Un epistolario es una cadena abierta: una carta no solo lleva a otras hacia adelante dirigidas al mismo interlocutor, sino que se ramifica en redes laterales, como muestra la carta anterior.

La lectura de estas cartas desemboca necesariamente en el encuentro amoroso de Octavio Paz con Marie José, su segunda mujer pero sobre todo su amiga y su musa quien, a partir de 1964, acompañará al poeta como una amable e inspiradora sombra. La huella luminosa de este misterioso personaje nacido en Marruecos atraviesa las cartas comentadas. Dos ejemplos: el 13 de noviembre de 1964 Martínez le escribe a Paz en la India: "Los Yáñez estaban muy contentos de haberte visto y muy impresionados por Marie José. Olivia decía con insuperable modo jalisciense: 'Debe ser muy bonito que lo quieran a uno así', yo creo que es cierto" (carta 28, p. 54). La otra huella, no luminosa sino iluminada es la que corresponde a la multicolor tarjeta postal con motivos hindús que representan una cámara nupcial y una pareja recién casada enviada por Octavio y Marie José y que Rodrigo Martínez transcribe en las páginas 69 y 70. En la tarjeta postal Marie José describe a sus amigos Lidia y José Luis Martínez tanto el ambiente en que está escribiendo como al propio Octavio Paz:

Chers amis,

L'été est fini, la mousson aussi - les pelouses anglaises redeviennent le "vert paradis" des écureuils, les jardins moghols celui des amoureux, et les massifs de bougainvilliers celui de noces exotiques d'oiseaux et de papillons resplendissants. Quel dommage que vous ne soyez pas avec nous pour découvrir, en ce mois d'octobre tiède et bleu, la nature recommencée de cet envoutant pays, tout régi par le rythme des saisons et par les dieux!

Octavio, plein dinspiration, écrit des tas de choses merveilleuses. Nous parlons souvent de vous et j'espère que nous nous reverrons bientôt.»

(Queridos amigos

El verano acabó, el monzón también; los pastos ingleses se vuelven nuevamente el "verde paraíso" de las ardillas, los jardines mogoles el de los enamorados, y los cuadros de buganvillas el de las nupcias exóticas de pájaros y de mariposas resplandecientes. Qué lástima que no estén ustedes con nosotros para descubrir, en este mes de octubre tibio y azul, la naturaleza vuelta a empezar de este país embrujado, regido todo por el ritmo de las estacionesy por los dioses! 
Octavio, lleno de inspiración, escribe muchísimas cosas maravillosas. Hablamos a menudo de ustedes y espero que nos volveremos a ver pronto).

La carta escrita a dos manos, en dos idiomas y a dos tintas, concluye con las noticias que da Paz a su amigo sobre su propio quehacer literario y poético. ¿No es verdad, querido Anthony, que una tarjeta postal puede encerrar las leyes de la hospitalidad que rigen el calendario de la amistad? Releamos a Octavio en esa tarjeta:

ya sea aquí o en París o en México o en cualquier otra parte - si, como creo, el mundo es un tejido de afinidades electivas (¿o fatales?). Por aquí han pasado varios Mexicanos y todos ellos, excepto el enigmático Yáñez, llenos de rumores políticoburocráticos... Nuestros paisanos esperan el $1^{\circ}$ de diciembre como la Edad Media el Año Mil o como los gnósticos la Segunda Vuelta. Por mi parte, fiel a mi taoísmo - dejarse mecer y conducir por la ola temporal- yo permanezco inmóvil y no deseo moverme... He escrito otro ensayo - ahora sobre Rubén Darío-. Ya me dirás tu opinión. Y otras cosas. El jardín -y el cielo entero de Delhi- se han cubierto de pájaros. No es extraño que Marie José y yo tengamos "la cabeza a pájaros". Y con esto, imitando a los loros y mirlos que desaparecen velozmente en pleno vuelo, nos despedimos con un abrazo.

“¿Quién de los dos escribe este poema?” se preguntaba otro poeta: se ve aquí dibujarse un yo plural y una sola sombra. Mientras Marie José contempla las "bodas exóticas de pájaros y de mariposas deslumbrantes", Paz se compara a sí mismo y a su pareja con los "loros y mirlos que desaparecen velozmente en pleno vuelo" al despedirse de "Uno de los poquísimos amigos verdaderos con que cuento en mi terrible país" (p. 72) y de su esposa. Lo siento, querido Anthony, me gusta releer: dice Octavio "no es extraño que Marie José y yo tengamos "la cabeza a pájaros"” (p. 69). Este conjunto de cartas encierra en su hospitalidad muchos pájaros, muchos entusiasmos: por estas páginas desfilan John Cage y Agustín Yáñez, Leonora Carrington y Henry Michaux, Rubén Darío y Luis Cernuda, además de los paisajes mismos de México y París, pero sobre todo, de la India: "La India es el gran abismo verde (ahora por el monzón) y mañana azul. Pasamos de la inundación a la sequía, de la epidemia de cólera al hambre, con regularidad cósmica. Pero Cali me protege. Escribo un texto largo sobre Darío. Temo que resulte un poco discursivo, reproche que ya le hiciste al Cernuda (jay!)".

Pongo por caso final el de la carta de Paz a Martínez del 11 de octubre de 1962 donde el poeta se dirige a su amigo: "Solo unas líneas - con un propósito interesado: recomendarte muy especialmente a la nueva canciller, señora Perla Pourcell. Te agradeceré muy de veras que le ayudes a aclimatarse. Es persona de gran competencia y a la que me siento ligado pero, como es natural, debe sentirse un poco 'fuera de ambiente'. Es la primera vez que sale al exterior. En realidad, yo fui el que le propuse salir y de ahí que me sienta un poco responsable - ante ti y ante ella. Gracias de antemano". ${ }^{16}$ Como ha informado oportunamente Guillermo Sheridan, ${ }^{17}$ quien transmite una información de don Ángel Gilberto Adame encontrada en El Nacional el 13 de diciembre de 1932: "El licenciado Octavio Paz es acusado por una señora", o sea el padre de Paz sedujo a María Raquel Poucel Aviña y tuvo con ella una hija, Perla Dina (1923-1991), quien fuera registrada con el nombre de sus abuelos. Más tarde Paz, como informa Felipe Gálvez en su libro Hoguera que fue (UAM, 1986), citado por Sheridan, al morir su padre conocería a la hija de la otra familia y, a partir de ese momento, experimentaría, al parecer, sentimientos de amistad y piedad filial. Dice "Octavio Paz en la memoria de Octavio Paz" en el libro de Gálvez: "A raíz de la muerte de mi padre supe que tenía una hermana. Un destacado político del callismo, amigo de mi padre, me encontró un día y me dijo: 'Tú tienes una hermana. ¿Quieres conocerla?’ Le respondí que sí y me llevó a visitarla. Desde entonces la trato, aunque no con la regularidad
16. Al calor de la amistad, p. 35 . 17. Guillermo Sheridan, “Octavio Paz y su padre: dramas de familia", El Universal, Opinión, 6 de mayo de 2014 . 
18. Octavio Paz Solórzano, Hoguera que fue, compilador Felipe Gálvez, UAM, 1986, p. 74. que yo quisiera. Es ella una mujer inteligente, que trabaja en el servicio exterior mexicano. Actualmente vive en Centroamérica y antes estuvo en Sudamérica. Pero nos comunicamos regularmente por la vía telefónica". ${ }^{18}$

\section{VII}

Las cartas están antes, por abajo o por encima, de la literatura. Muestran a los seres humanos en su más viva intensidad, este epistolario, cuidadosamente trabajado por Rodrigo Martínez Baracs, es un ejemplo de ello. Las cartas aquí reunidas son desde luego momentos aislados y singulares de un paisaje más amplio. Pueden servir para reconstruir parcialmente la vida y avatares - premios, publicaciones, empresas-de los corresponsales. Estas cartas nos dejan con la sensación clara de que falta todavía mucho trabajo en relación con el proyecto de editar alguna vez el epistolario de Octavio Paz del cual estos papeles son apenas unas cuantas muestras. Pero las cartas cruzadas entre Martínez y Paz dan idea de lo que puede significar el "calor de la amistad".

La publicación de un epistolario es siempre un acontecimiento. La carta tiene, en el universo de las letras, un estatuto epistemológico y estético singular, a caballo entre el documento y el monumento, Cioran pensaba incluso que la carta es un género superior al poema, el ensayo y el cuento, pues podría incluirlos y además formar parte de esa otra expresión a la vez documental y monumental que es el diario. La publicación de un epistolario mueve el pensamiento, tanto como las emociones públicas, domésticas y privadas.

Al calor de la amistad se titulan las cartas que van de 1950 a 1984 y que consta de 76 mensajes y tres apéndices. El título, como advierte Rodrigo Martínez Baracs, su filial editor, se deriva de una frase dicha por el poeta al crítico: "proviene de una historia que me contó mi padre. En uno de sus últimos días, cuando Octavio se encontraba ya muy enfermo, mi padre le puso la mano en el hombro. Entonces Octavio le puso la mano sobre la suya y le dijo: "Tu mano tiene el calor de la amistad sincera'". Al calor de la amistad: en efecto, la amistad puede ser cálida y abrigadora como una buena capa que nos protege de la intemperie, pero, por lo que se ve en este valioso epistolario, es también necesariamente práctica, diligente, cuidadosa, eficaz, sincera, militante y trabajadora: es capaz de hacerse cargo del menaje de la mudanza del amigo diplomático al tiempo que no le escatima las verdades y las críticas, aunque tampoco se ahorra molestias para reservar un hotel, cumplir uno y otro encargo del amigo para otro amigo, como fue el caso de ciertos objetos exóticos que compró Henri Michaux, de Paz, en la India y de los cuales se responsabilizó su amigo el impecable y santo José Luis Martínez, quien se hizo amigo del poeta. Nada más sorprendente que imaginar juntos al mexicano prudente y al francés delirante. La amistad produce así archipiélagos de amigos movidos por la simpatía recíproca creando una constelación, una familia de individuos elegidos y electivos, movidos por una causa eficiente ( $\dot{\text { lla }}$ de la justicia, la verdad, la belleza, las letras, la contemplación?) que los atraviesa y los pone en contacto a su vez, aunque ellos no lo sepan, con otras constelaciones, con otros archipiélagos, con otras familias espirituales. Ese es quizá el nervio mismo de una Academia. Es muy probable que José Luis Martínez fuera pudoroso y probablemente en vida no hubiese dado a la estampa este epistolario con su admirado y querido amigo.

La correspondencia cruzada entre Paz y Martínez remite al contraste y comparación entre dos itinerarios intelectuales y literarios a la par muy distintos y en cierto modo complementarios: el de un poeta y ensayista como Octavio Paz - guerrero nómada - y el de su lector eficiente y amigo, (al decir de Gabriel Zaid) curador y urbanista 
de la ciudad literaria, el crítico y editor, José Luis Martínez, ambos discípulos y lectores de Alfonso Reyes y del grupo de escritores congregados en torno a la revista Contemporáneos, encabezados por Xavier Villaurrutia, ambos desvelados desde muy temprano por el sentido pasado y presente de la literatura escrita en español desde México.

\section{VIII}

Como puedes ver querido Anthony, Octavio era capaz de hacer convivir en unas pocas líneas a los dioses y a los hombres, al milagro y a la fatalidad y pasar de la observación meteorológica a la bitácora del escritor y del escritorio. En la tarjeta postal del 16 de octubre de 1965 revela uno de sus secretos: "fiel a mi taoísmo - dejárseme ser y conducir por la ola temporal-yo permanezco inmóvil y no deseo moverme". Quizás se escribe para no moverse, quizás se escribe a los amigos para imitar la inmovilidad de la roca en la montaña. Quizás esta sea, querido Anthony Stanton, una de las lecciones de este epistolario. Recibe, como le gustaba decir a Octavio, "un abrazo del tamaño del Ganges" (carta 18 de septiembre de 1964). 
